\title{
Editorials
}

\section{The inverse care law revisited:}

\author{
a continuing blot on the record of the National Health Service
}

\section{THE PERSISTENCE OF THE INVERSE CARE LAW}

'The availability of good medical care tends to vary inversely with the need for it in the population served."

The monstrous longevity of the inverse care law, almost half a century after it was first described in the UK NHS, reflects poorly on politicians, NHS management, and professional organisations, all of whom regularly assert their opposition to inequalities in health and health care. As Tudor Hart observed, intellectual opposition to injustice is only the beginning of social understanding?

In his later years, Tudor Hart regretted having coined a term that had entered action.

\section{MARKET FORCES THREATEN THE NHS}

Tudor Hart's original essay emphasised that the inverse care law operates more completely where medical care is most exposed to market forces, and less so where such exposure is reduced. Commercial does not pay for the training of the staff it employs; excludes patients who cannot pay; avoids complexity whenever it can; panders to the worried well; and over-provides in promotes social exclusion at both ends of society, excluding patients who cannot pay, and affluent patients who no longer have a stake in a shared system.

The introduction of the NHS is often commemorated as if it were a battle, like Waterloo, at which a national enemy was defeated for all time. A better analogy is a Dutch dyke, keeping the sea at bay. If the dyke is not maintained, the defence will sooner or later be breached. Such is the lucrative nature of medical trade that commercial motives in health care are never far away. US corporate health care is always looking to expand in what it sees as untapped European markets. In recent years, it seems they have a fifth column in Whitehall. The Prime Minister has refused to rule the NHS out of possible trade deals with the US if and when the UK leaves the European Union.

Government has abetted the process by underfunding the NHS and stimulating the vocabulary but had not led to effective medicine takes money out of the system; terms of investigations and treatments. It

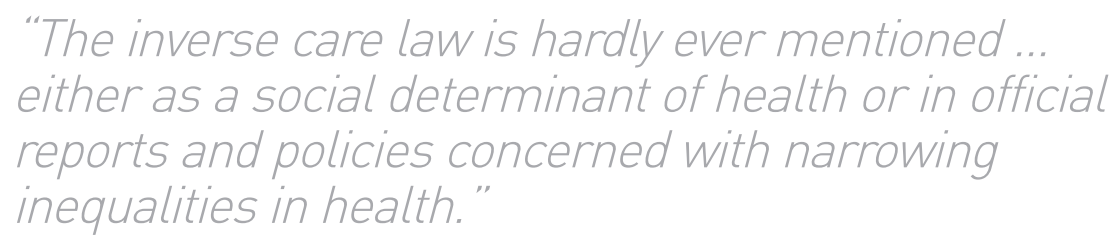

"The inverse care law is hardly ever mentioned... either as a social determinant of health or in official reports and policies concerned with narrowing inequalities in health.

demand for alternative sources of care by those who can afford it. Having sleepwalked into the financial horror of the Private Finance Initiative, the health professions and general public, in England in particular, appear to be sleepwalking into the social horror of market forces determining the future of the NHS.

When asked how long he thought the NHS would survive, Aneurin Bevan replied, For as long as there are people prepared to fight for it.' Patients and practitioners are being put to that test now.

\section{IMPROVED EFFECTIVENESS OF CARE BUT VARIABLE DELIVERY}

Tudor Hart's second explanation of the inverse care law presents another big political challenge. ${ }^{3}$ As health care has become more effective, not only via the delivery of evidence-based medicine but also the better organisation of personalised continuity of care, ${ }^{4}$ its mass delivery improves population health, especially in later life. The corollary is that if such care is delivered inequitably, for example, as a result of the inverse care law, inequalities in health will widen. The inverse care law is hardly ever mentioned, however, either as a social determinant of health or in official reports and policies concerned with narrowing inequalities in health. McKeown's orthodoxy, that health care contributes little to public health, still prevails despite huge advances in the effectiveness and organisation of care. ${ }^{5}$

Most countries (even the US) pass the test of providing universal access to emergency medical care, but this is only one aspect of a decent healthcare system. Most patients, and especially the increasing numbers with multimorbidity, need access to primary medical care, offering first contact and unconditional, personalised continuity of care, complemented by access to specialist investigations and treatments on occasion. Patients who are satisfied with such care, and whose disease complications have been prevented, postponed, or lessened, live longer in the community and are less likely to access emergency care.

The generally flat distribution of GPs across the UK means that, although virtually everyone has access to primary medical care, the distribution of needs-based care is socially patterned. ${ }^{6}$ Consultations in deprived areas are characterised by increased multimorbidity, shorter duration, lower expectations, lower enablement lespecially for mental health conditions, which are the commonest comorbidity in deprived areas), poorer outcomes, and greater practitioner stress. ${ }^{7-9}$ Although affluent patients with multimorbidity get $25 \%$ longer consultations, similar patients in deprived areas get no additional time. ${ }^{10}$ The consequences are unmet need, poorly coordinated care, and greater reliance on unscheduled care services - modern manifestations of the inverse care law.

\section{SYSTEMIC DISADVANTAGES FOR PATIENTS IN DEPRIVED AREAS}

The GP contract continues as a corrupt funding mechanism with two competing purposes - paying doctors and resourcing care. Channelling more money via this mechanism provides no guarantee as to

\section{"The inverse care law is not a law, but the consequence of policies that restrict needs-based care in communities with the poorest health.}




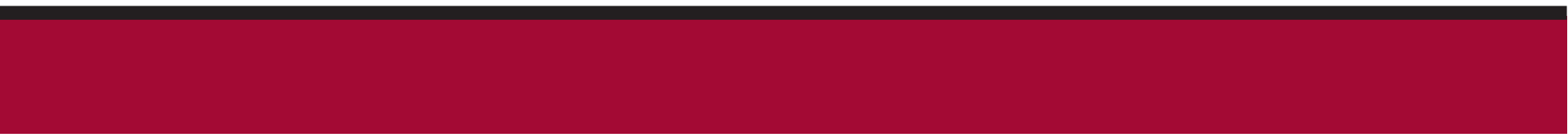

\section{"The political and medical establishments have turned a blind eye to the inverse care law and their role in keeping it alive.}

how the additional funds will be spent. Redistribution of funding within the contract is a non-starter when the whole system is underfunded and everyone feels under pressure. Scotland's First Minister, Nicola Sturgeon, said in the Scottish Parliament that the needs of practices in deprived areas would be addressed via the new Scottish GP contract. Professional opposition put an end to that.

Walton and colleagues in this issue provide an additional twist in their qualitative study comparing the views and experience of GPs serving affluent and deprived areas, concerning the referral of patients to cardiology services. ${ }^{11}$ Patients in deprived areas who lack health literacy, confidence, and agency are less likely to seek referral whereas affluent patients are more likely to demand it. Patients in deprived areas are not hard to reach but they are easy to ignore and are more likely to be ignored in a timepoor service.

\section{ARE HEALTH SYSTEMS SERIOUS ABOUT ADDRESSING THE INVERSE CARE LAW?}

When GPs serving the 100 most deprived communities in Scotland met in 2009 it was the first time in the history of the NHS that this group had been convened or consulted. They also had been easy to ignore. There are now Deep End groups of GPs in Scotland, Ireland, Yorkshire/ Humber, and Greater Manchester. ${ }^{12-15}$ If the health systems in the UK and Ireland are serious about addressing the inverse care law, they will have to engage and support these groups and others like them pro rata based on need.

The inverse care law in general practice is not the difference between good and bad medical care; it is the difference between what practitioners are able to do and what they could do with more time and better links to other resources. Tudor Hart led the way with his own example as a 'worried doctor', embedded in a community, anticipating patients' problems and not waiting until they had happened. ${ }^{16}$ After 25 years in practice he showed that premature mortality was $28 \%$ lower in his patients compared with a neighbouring village. ${ }^{17}$

Heroic individual achievements are no substitute for public policy. The inverse care law is not a law, but the consequence of policies that restrict needs-based care in communities with the poorest health. Noisier, more assertive, and more powerful interests hold sway. There is a disconnect between the rhetoric of addressing health inequalities and the reality of health care where it is needed most. The political and medical establishments have turned a blind eye to the inverse care law and their role in keeping it alive. The question arises: is the NHS an instrument to address social injustice, reducing unfairness in society, or is it not?

\section{Graham Watt,}

Emeritus Professor, General Practice and Primary Care, University of Glasgow, Glasgow.

\section{Provenance}

Commissioned; not externally peer reviewed.

\section{Competing interests}

Graham Watt was the coordinator of General Practitioners at the Deep End from 2009-2016.

DOI: https://doi.org/10.3399/bjgp18X699893

\section{ADDRESS FOR CORRESPONDENCE}

Graham Watt

University of Glasgow, General Practice and

Primary Care, Glasgow G12 9LX, UK.

\section{Email: Graham.Wattaglasgow.ac.uk}

\section{REFERENCES}

1. Hart JT. The inverse care law. Lancet 1971; 1(7696): 405-412.

2. Hart JT. Relation of primary care to undergraduate education. Lancet 1973; 2(7832): 778-781.

3. Watt $\mathrm{G}$. The inverse care law today. Lancet 2002 ; 360(9328): 252-254

4. Pereira Gray DJ, Sidaway-Lee K, White E, et al. Continuity of care with doctors - a matter of life and death? A systematic review of continuity of care and mortality. BMJ Open 2018; $\mathbf{8 ( 6 ) :}$ e021161.

5. Mckeown T. The role of medicine: dream, mirage or nemesis? London: Nuffield Trust, 1976.

6. McLean G, Guthrie B, Mercer SW, Watt GCM. General practice funding underpins the persistence of the inverse care law: cross-sectional study in Scotland. Br J Gen Pract 2015; DOI: https://doi.org/10.3399/ bjgp15X687829.

7. Mercer SW, Watt GCM. The inverse care law: clinical primary care encounters in deprived and affluent areas of Scotland. Ann Fam Med 2007; 5(6): 503-510.

8. Mercer SW, Higgins M, Bikker A, et al. General practitioners' empathy and health outcomes: a prospective observational study of consultations in areas of high and low deprivation. Ann Fam Med 2016; 14(2): 117-124.

9. Barnett K, Mercer SW, Norbury M, et al Epidemiology of multimorbidity and implications for health care, research, and medical education: a cross-sectional study. Lancet 2012; 380(9836): $37-43$

10. Mercer SW, Zhou Y, Humphris GM, et al. Multimorbidity and socioeconomic deprivation in primary care consultations. Ann Fam Med 2018; 16(2): 127-131.

11. Walton E, Ahmed A, Burton C, Mathers N Influences of socioeconomic deprivation on GPs' decisions to refer patients to cardiology: a qualitative study. Br J Gen Pract 2018: DOI: DOI: https://doi.org/10.3399/bjgp18X699785.

12. GPs at the Deep End. https://www.gla.ac.uk/ deepend (accessed 24 Oct 2018).

13. Deep End Ireland. http://deepend.ie laccessed 24 Oct 2018).

14. General Practice at the Deep End Yorkshire and Humber. https://yorkshiredeependgp.org laccessed 24 Oct 2018).

15. Sharedhealth foundation. Tackling inequalities in health across Greater Manchester. https://www. sharedhealthfoundation.org.uk/deepend-gm (accessed 29 Oct 2018).

16. Hart JT. A new kind of doctor: the general practitioner's part in the health of the community. London: Merlin Press, 1988.

17. Hart JT, Thomas C, Gibbons B, et al. Twenty five years of case-finding and audit in a sociallydeprived community. BMJ 1991; 302(6791): 1509-1513. 